\title{
MOVILIDAD, PARENTESCO E IDENTIFICACIÓN EN EL VALLE DE CODPA, NORTE DE CHILE
}

\author{
MOBILITY, KINSHIP AND IDENTIFICATION IN THE \\ CODPA VALLEY, NORTHERN CHILE
}

\author{
Cristhian Cerna ${ }^{1}$ y Wilson Muñoz $2,3,4$
}

\begin{abstract}
Este artículo analiza la relación entre movilidad, migración rural-urbana, prácticas de parentesco e identificación colectiva de los habitantes del Valle de Codpa, localidad ubicada en la Precordillera de Arica, extremo norte de Chile. La metodología de la investigación involucró la conjunción del método de caso extendido y la etnografía multi-situada. Entre 2012 y 2017 , llevamos a cabo una etnografía en espacios urbanos y rurales a través de los cuales los miembros conectan la ciudad de Arica con la localidad. A partir de los resultados de la investigación, mostramos que en un contexto de alta migración rural-urbana que caracteriza a los territorios indígenas diagnosticados como despoblados, las prácticas de parentesco han sido claves en la configuración de una identificación translocal de la población, dando cuenta del funcionamiento de una lógica sociocultural específica asociada a la localidad y su construcción de alteridades en la frontera (trans)nacional.
\end{abstract}

Palabras claves: movilidad-migración, parentesco, identificación, Andes, norte de Chile.

This article analyzes the relationship between population mobility, rural-urban migration, kinship practices and collective identification in the Codpa Valley, located in the Arica Precordillera in northern Chile. The research methodology combined the extended case method and multi-sited ethnography. Between 2012 and 2017, we carried out ethnography in urban and rural spaces through which members connect the city of Arica with the locality. Based on the results of the research, we show that, in a context of high rural-urban migration that characterizes the indigenous territories diagnosed as depopulated, kinship practices have played a central role in the configuration of a translocal identification of the population, revealing a specific sociocultural logic associated with the locality and its construction of alterities in the (trans)national border area.

Key words: Mobility-migration, kinship, identification, Andes, northern Chile.

Desde fines del siglo XIX, las comunidades andinas del extremo norte de Chile se fueron insertando en los modelos de desarrollo y modernización regional. Esto generó cambios a nivel sociocultural, económico, político, territorial y poblacional, siendo una de sus consecuencias la pauperización de las condiciones de vida de las comunidades (González et al. 2014:240; Gundermann 2005:63, 2013:96, 2018:95; Gundermann y González 2008:86; 2009a:108, 2009b:135; Lima et al. 2016:7). Posteriormente, a mediados del siglo
XX, ocurrió la migración y radicación de dos tercios de la población rural andina en diversas ciudades de la región y el país (Bähr 1980, 1985; Castro 1982, 1997; González 1990, 1996, 2007; Gundermann 1998, 2001; Tabilo et al. 1995). Desde entonces la investigación catalogó a los territorios andinos en estado de despoblamiento, reproduciendo una concepción basada en la discontinuidad entre lo rural y lo urbano, apelando a las características sociodemográficas y económicas de esta población. El fenómeno mantuvo sus características constantes,

\footnotetext{
${ }^{1}$ Facultad de Ciencias Sociales, Universidad de Tarapacá, Arica, Chile. ORCID ID http://orcid.org/0000-0001-6117-2381. cristhiangcerna@gmail.com

${ }^{2}$ Laboratoire d'Anthropologie Sociale (LAS), Collège de France/EHESS/CNRS, Paris, France.

${ }^{3}$ Investigacions en Sociologia de la Religió (ISOR), Departamento de Sociologia, Universitat Autònoma de Barcelona, Barcelona, España.

${ }^{4}$ Facultad de Educación y Humanidades, Universidad de Tarapacá, Arica, Chile. wilsonsocio@gmail.com
}

Recibido: abril 2018. Aceptado: noviembre 2018. 
llamando la atención la sostenibilidad demográfica que se fue instalando y la presencia de recambio de residentes, no llegándose a cumplir la hipótesis del colapso demográfico (González 2007).

En la década de 1980, el fenómeno fue abordado bajo enfoques ecológicos y culturalistas. Las investigaciones subrayaron las particularidades del patrón migratorio seguido por la población indígena, el cual fue explicado recurriendo a la tesis de la aculturación y de la inserción parcial de la población en los circuitos del mercado capitalista (Grebe 1986, 1997; Gundermann y Chipana 1986). En la década de 1990, los estudios revelaron la existencia de una serie de estrategias de ocupación multiresidencial de los actores andinos. Las principales características de la sociedad indígena regional eran la desruralización, desagrarización, descampesinización y translocalidad. Así, la comunidad andina aparecía enmarcada en una red de flujo constante de personas, bienes y elementos simbólico-identitarios (Carrasco y González 2012, 2014; González 2007; González y Gundermann 1996; Gundermann y González 2009a, 2009b). Bajo esta nueva perspectiva, la comunidad andina regional vivía entonces un fenómeno de postcomunalidad propiciado por la migración y movilidad de la zona.

Haciendo eco del giro culturalista que dieron las ciencias sociales en los años noventa (Marcus y Fisher 1999), entrado el siglo XXI se volvió a revisitar este fenómeno, haciendo hincapié esta vez en el rol que tenía la denominada agencia social (Carrasco y González 2014; Gundermann y González 2008). Se volvió relevante develar el sentido que le atribuían los actores a su acción social en este nuevo escenario. En este marco, la localidad rural aparece como un lugar imaginado y referencial que es convocado en las prácticas de los actores andinos, permitiéndoles así re-elaborar sus vínculos colectivos (Paerregaard $2010,2011)$ y las redes interpersonales estructuradas según localidad de origen y parentesco (Gundermann y González 2008).

Aquí fue clave el uso de la noción de translocalidad para conceptualizar el cambio en la configuración espacial de las relaciones comunitarias, la cual pasaba a operar desde el ámbito local a esferas más generales y globalizadas (Gundermann 2018; Paerregaard 2010, 2011). Así, de un proceso histórico de regionalización indígena, que tenía como substrato principal a la comunidad rural, real o evocada, con sus límites que se inscriben en las fronteras de lo local y comunitario, se transita a un periodo basado en manifestaciones supra-locales; donde el soporte principal ya no es únicamente la comunidad en el territorio concreto, rural y/o ancestral, sino también otras colectividades derivadas de la transformación económica, social y cultural de la región. Esta noción permitió comprender el re-establecimiento de la correspondencia y diferenciación entre los miembros de la comunidad andina en el escenario de cambios y continuidades estructurales, donde la adquisición de nuevos elementos de socialización intra-comunitaria operarían como claros recursos de identificación (Albó 1972, 2000; Gölte 2012; Harris 2008; Harvey 1998; Malengreau 2008; van Vleet 2008); especialmente aquellos que utilizan al terruño como evocación del lugar de origen y pertenencia (Malengreau 2008).

En este artículo quisiéramos contribuir al desarrollo de esta línea de estudios, poniendo a prueba la tesis antes mencionada a través del análisis de un caso etnográfico y sus particularidades. Nuestro objetivo es analizar la relación que existe entre la movilidad campo-ciudad, el parentesco y la identificación de los actores codpeños. Nuestra hipótesis de trabajo es que en un contexto de alta movilidad y migración campo-ciudad, las prácticas de parentesco se han vuelto significativas para la re-configuración de una identificación translocal de los codpeños, apreciándose la operación de una lógica cultural andina específica que codifica esta experiencia.

En este estudio utilizamos el concepto de identificación en vez de identidad. Consideramos que frente a la polisemia y vaguedad de este último (Dubet 1987), el concepto de identificación se refiere a un proceso más específico y útil para iluminar nuestro caso de estudio. La identificación considera el momento específico del enganche o sujeción de algo (sujeto, idea), el cual constituiría a los actores en un momento particular y específico de su identidad histórica y contextual, por lo que puede variar (Navarrete 2015:468). Además, suele ser utilizado para referirse a un aspecto o una de las formas de este vínculo, sin necesidad de referirse al fenómeno como una experiencia unitaria ni excluyente de otras identificaciones. De esta forma, contribuye a entender mejor el proceso de construcción identitaria (Hall 2000). Esto es útil para identificar la presencia de una lógica cultural andina específica, la cual contempla aquellos elementos y relaciones que asumen valores significativos en nuestra zona bajo estudio.

Para abordar de manera óptima nuestro objeto de estudio, utilizamos como estrategia metodológica la etnografía multi-situada y el análisis de caso extendido. La combinación de ambas estrategias nos permite comprender la naturaleza específica del objeto estudio y sus dinámicas, siendo especialmente sensible a su condición de movilidad. Hemos tomado como caso de estudio a los habitantes del Valle de Codpa, los cuales se caracterizan por tener una alta movilidad entre el valle y la ciudad de Arica (principalmente). 
El Valle de Codpa se ubica a una altitud promedio de $1800 \mathrm{msm}$ en la precordillera y a solo $113 \mathrm{~km}$ de la ciudad de Arica (Figura 1). Siendo uno de los centros neurálgicos de la administración política y eclesial durante parte importante de la Colonia, a lo largo del siglo XIX y especialmente el siglo XX sufrió fuertes procesos migratorios que llevaron a su población a emigrar y trasladarse a la principal ciudad de la región: Arica. Desde entonces, la movilidad de sus habitantes entre ambos lugares (entre otros) ha sido una de sus características más distintivas. Las principales técnicas de producción de información utilizadas fueron: la observación participante, cuyo objetivo era obtener información sobre las dinámicas de parentesco y movilidad directamente; y la entrevista semi-estructurada en profundidad, cuyo objetivo era relevar información genealógica que permitiera conocer la estructura social estamentaria de la población del valle. Se realizaron 40 entrevistas en profundidad a diferentes actores locales: 25 mujeres, de las cuales 18 poseían adscripción aymara y siete no poseían adscripción indígena; y 15 hombres, de los cuales nueve poseían adscripción aymara y seis no poseían adscripción indígena. Adicionalmente se aplicaron fichas de caracterización con el fin de obtener información sociodemográfica sobre todos los entrevistados. La recolección de datos se realizó durante los años 2012 y 2017. Toda la información fue triangulada y luego analizada siguiendo los principios de la teoría fundamentada.

El artículo se estructura de la siguiente manera. Primero realizamos una descripción etnográfica de algunas dinámicas socioculturales de la comunidad en el Valle de Codpa, considerando la historicidad del proceso de migración-movilidad territorial y su vinculación con las identificaciones de los actores. Posteriormente examinamos el rol de las prácticas de familia y el parentesco en el establecimiento de las relaciones sociales que formulan los sujetos bajo estudio. En tercer lugar, discutimos los datos etnográficos a la luz de los modelos de interpretación de la alteridad local y la diferenciación comunitaria para la zona andina del norte de Chile. Finalmente, entregamos algunas consideraciones generales sobre nuestros hallazgos.

\section{Dinámicas de Identificación: Natos y Afuerinos}

A inicios del siglo XX, el Valle de Codpa vivió un momento de depresión socioeconómica y poblacional, unida a una escasa conectividad vial con los principales centros urbanos de la región. Esto contribuyó a crear una imagen de relativo aislamiento territorial en el valle a la vez que se producía una intensa intervención por parte del Estado chileno. Caracterizada por la presencia de una ideología "chilenizadora" que era parte de un sistema de dominación nacional, se reconfiguraron así el acceso y control de la producción de un discurso público y legitimado por las élites locales sobre "nosotros". Posteriormente, la intensificación de los flujos migratorios regionales y luego transfronterizos, afectó con mayor rigor el contexto local. Este nuevo escenario nutrió al imaginario local con nuevos elementos de identificación, complejizando las clasificaciones sobre lo propio y lo ajeno, tanto a nivel social como territorial.

A partir de la década de 1940 se produjeron las primeras oleadas de emigración local hacia la ciudad de Arica. Esta fue protagonizada principalmente por cohortes jóvenes que buscaban proseguir sus estudios o incorporarse al mercado laboral asalariado. Tal evento produjo un drástico cambio en los modos de vida de este segmento. Por un lado, los residentes vivenciaron la ampliación de los márgenes de sus unidades domésticas, desde donde se elaboran estrategias de movilidad campociudad. Por otro lado, también se fue recreando e incorporando la figura virtual del "valle" originario como un recurso de identificación cultural en la urbe. Así, se consideró al espacio territorial del valle como un factor simbólico clave en la construcción de una comunalidad codpeña, más allá del lugar efectivo y permanente de residencia de los actores. No obstante, también hubo un grupo importante de población más envejecida que se mantuvo residiendo en el Valle de Codpa, quienes fueron reactualizando su pertenencia a este lugar regulando diversos arreglos sucesorios vinculados a la propiedad de la tierra y a su residencia en el territorio. En este nuevo escenario, una de las distinciones más importantes que estableció la población para identificar a los actores fue entre quienes eran codpeños "natos" o legítimos, y quienes eran "llegados" o afuerinos.

\section{Los natos}

Un pueblo es una casa, porque yo al entrar a un pueblo dentro [sic] por la puerta, ¿no cierto?; y seguimos siempre esa mente. A ver. Mis padres y mis abuelos son de acá. Yo también nací acá. Soy de mi pueblo, y soy del valle. Yo me crié acá. Estoy acá. Por eso, hay una diferencia entre el codpeño legal y la gente de afuera (entrevista I18/E20, hombre, 74 años, poblado de Guañacagua).

La opinión recién citada de nuestro entrevistado de Guañacagua la encontramos a lo largo de todo el 


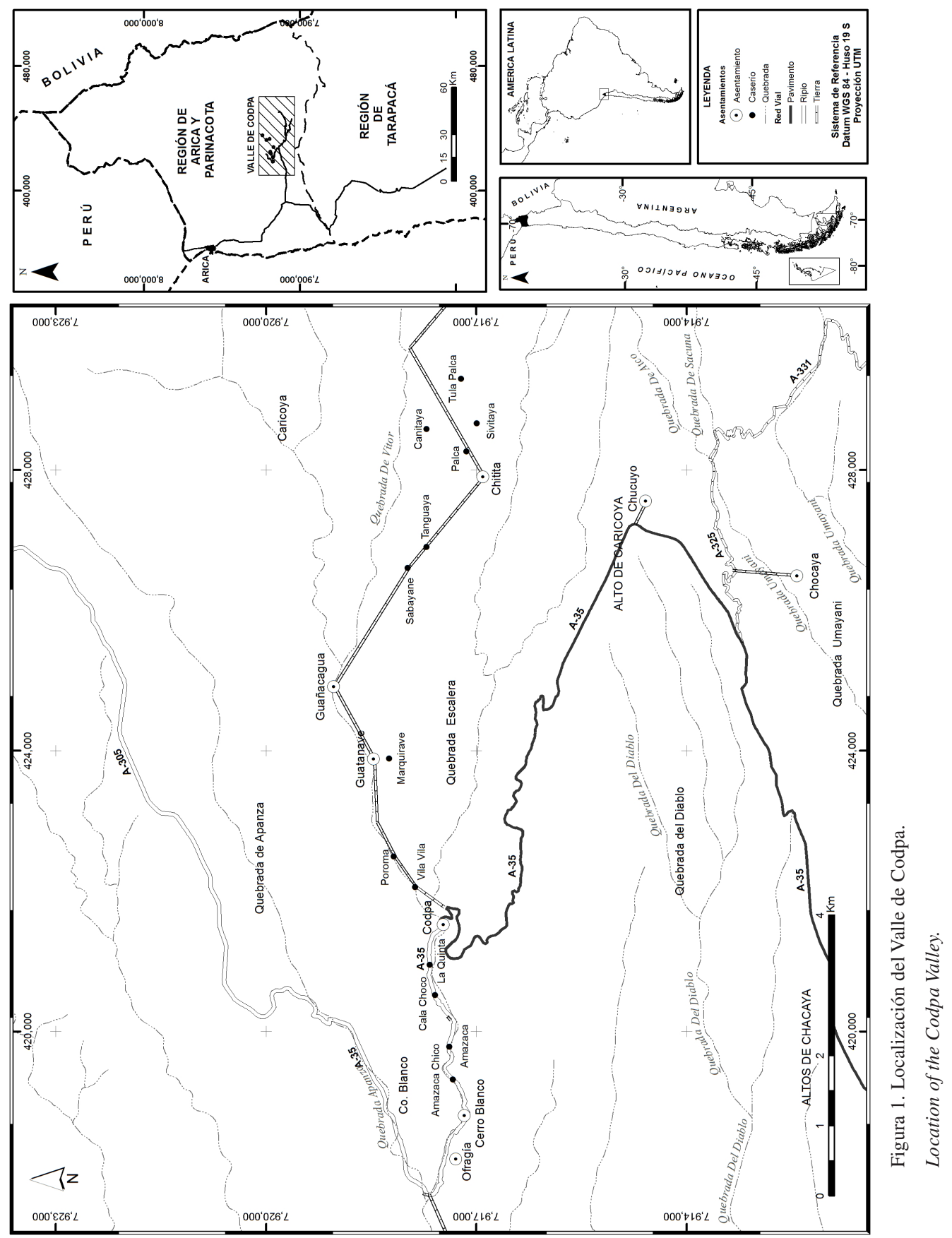


Valle de Codpa. Como bien señala, tanto sus raíces parentales, como el lugar de su crianza y residencia actual, le permiten afirmar fehacientemente que él es un codpeño "legal" o nato, diferenciándose inmediatamente de la gente de "fuera".

En general, los codpeños considerados natos son actores que suelen utilizar lógicas de identificación de descendencia cognaticia, la cual les otorga mayor legitimidad en el valle. Suelen reproducir un sistema de parentesco clasificatorio agnaticio vinculado a los actores históricos que protagonizaron la llegada original al valle, o que adquirieron tierras por compraventa o herencia a fines del siglo XIX. Además, normalmente incorporan en su definición y clasificación de familia y comunidad a parientes afines y consanguíneos, estableciendo así una clara distinción con otros actores locales (Figura 2). En este grupo es posible identificar la presencia de un parentesco ascendente, descendente y/o lateral como base. Esto se refuerza mediante la participación de estos actores en actividades comunitarias, festivorituales y de desarrollo territorial (Figura 3).

Las limitaciones económicas y socioeducativas que atravesó el valle durante parte importante del siglo $\mathrm{XX}$, lo convirtieron en un lugar donde la movilidad social estaba fuertemente limitada. En este contexto, las dinámicas de movilidad que aún caracterizan a la zona configuraron una nueva relación campociudad. La relocalización permanente de muchos de sus miembros en Arica tuvo como uno de sus principales efectos la emergencia de nuevas cohortes de individuos que se considerarán, de ahora en adelante, descendientes de las familias identificadas como históricas en Codpa. Esto ha permitido que las dinámicas comunitarias no se realicen de manera exclusiva a partir de las bases territoriales afincadas efectivamente en el valle. De manera paralela, Codpa fue catalogado como un recurso de identificación y de patrimonio, pero no como un espacio de realización socioeconómica ni hábitat para la residencia estable.

Actualmente el segmento más joven de descendientes codpeños suele estar en edad escolar o en edad económicamente activa, y tiene su residencia principal en la ciudad de Arica, aunque también (en menor medida) en otros centros urbanos de la macro zona norte, y/o del centro del país. En general, los descendientes tienden a actualizar principios de parentesco de tipo bilateral y con criterios cognaticios. Este conjunto de relaciones nutre la identificación codpeña, propiciando además la integración, diferenciación y realización comunitaria virtual (postcomunitaria). Esta configuración va modulando la movilidad intercomunal e interregional de la población local, donde las relaciones próximas son un catalizador clave en estos procesos. Estos grupos se han distanciado de las labores directas vinculadas con la producción agrícola del valle. No obstante, su vinculación con Codpa se ha realizado a través de dos vías que pueden coexistir.

Por un lado, la vinculación se ha realizado a través de la participación en una serie de iniciativas de tipo cultural-identitarias que desde la ciudad buscan promover el patrimonio cultural andino. Estas actividades se han realizado de manera normal siguiendo los cánones etnogubernamentales vigentes sobre lo "indígena", y particularmente sobre lo "aymara", complementado con recursos locales de identificación colectiva, aunque no sin la ausencia de diferencias y controversias internas. Y, por otro lado, a través de la asistencia al valle durante el periodo de celebración de festividades, donde muchas veces la reproducción de estas celebraciones es vista como una forma de salvaguardar el patrimonio cultural, promover la identificación con el valle y apoyar su desarrollo. Una de las estrategias que ha sido utilizada para impulsar este tipo de actividades ha sido la creación y suscripción en organizaciones territoriales (como la Comunidad Indígena Pueblo de Codpa, la Comunidad Indígena Aymara de Guañacagua, la Agrupación Indígena Cultural Raíces Codpeñas, la Agrupación Cultural, Social y Deportiva Codpa Valle Querido, entre otras), generando además la imagen de una mayor población efectiva en el territorio.

No obstante, tanto la residencia permanente, como la actividad principal y el tipo de vínculo con el territorio codpeño -fundado tradicionalmente en la propiedad y derechos de tierra y agua, y sus sistemas formales y consuetudinarios de transmisión o herencia-, pueden cambiar. Especialmente cuando estos actores terminan sus actividades productivas en la ciudad y acceden (en muchos casos) a su jubilación, o bien cuando son marginados del mercado laboral. En este contexto pueden decidir relocalizar su residencia permanente en el Valle de Codpa, entre otras cosas porque el coste de vida es menor, es más fácil acceder a una propiedad, pueden acceder a pequeños trabajos remunerados, o simplemente porque de esta manera cumplen con el antiguo anhelo de retornar a su pueblo de origen y/o estar más próximos de sus ancestros sepultados en los cementerios del sector.

\section{Los afuerinos}

La histórica migración (trans)fronteriza ha configurado en gran medida no solo la dinámica del flujo poblacional del Valle de Codpa, sino también la construcción de sus formas de identificación, dentro de la cual se construye además la alteridad intracomunitaria. En este contexto, el grupo de los considerados afuerinos se ha ido conformando principalmente por inmigrantes 


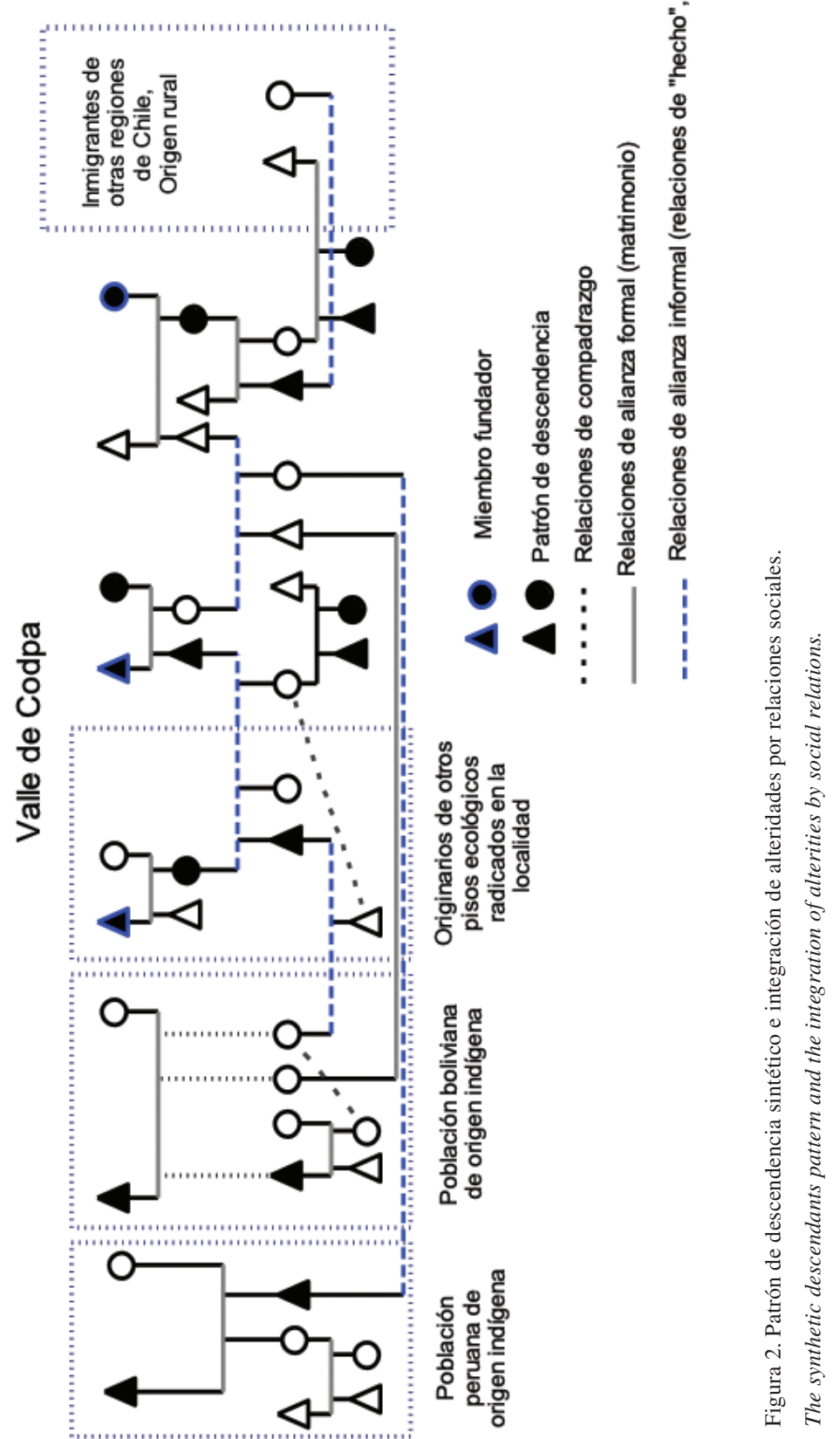




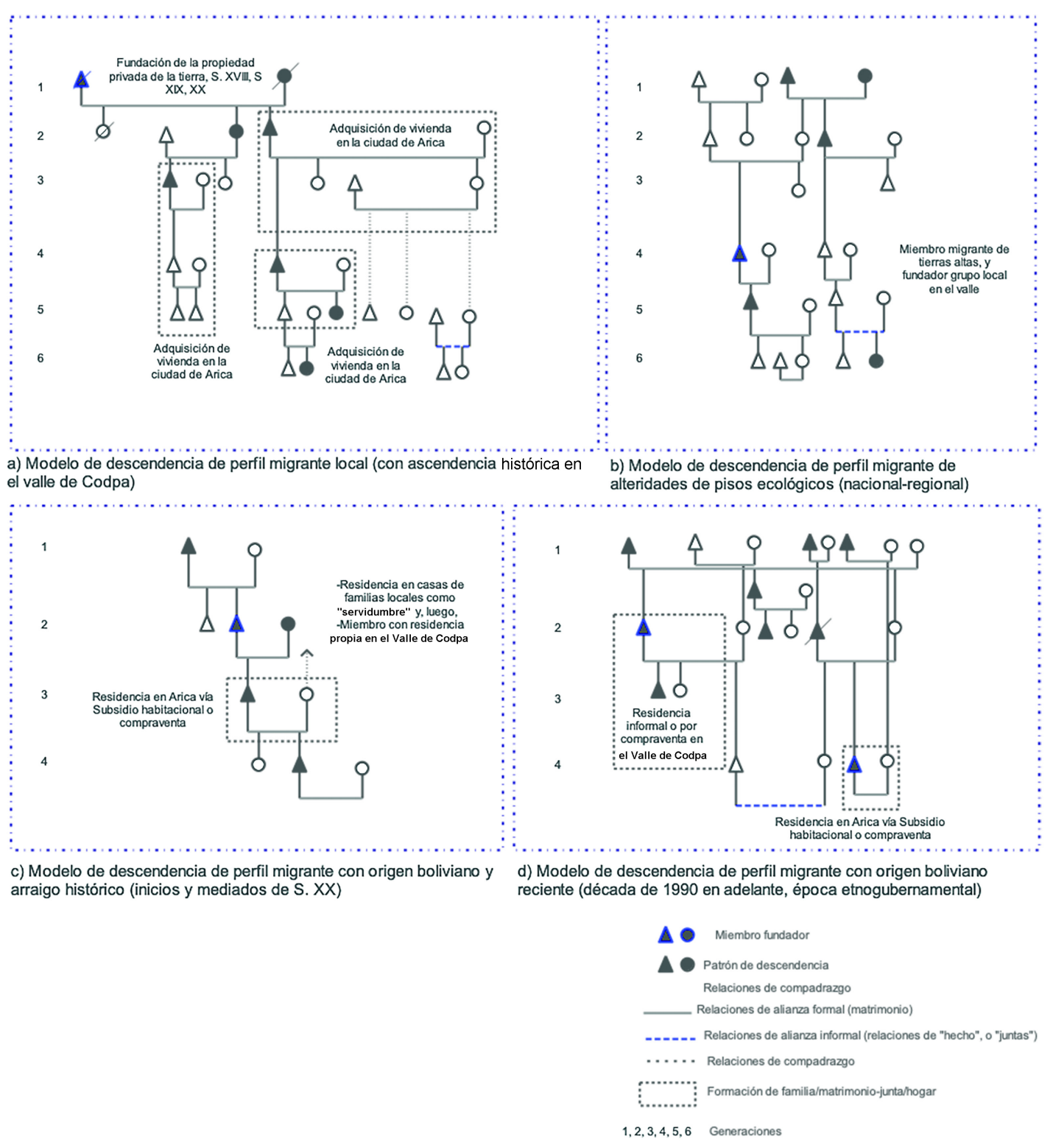

Figura 3. Modelos de descendencia de las alteridades locales principales.

Models of descendants of the main local alterities.

provenientes de otras zonas micro-regionales y/o cotas altitudinales del espacio andino-nacional, inmigrantes indígenas de origen boliviano, y en menor medida incluso por indígenas de origen peruano e inmigrantes de otras regiones del país sin pertenencia indígena (Figura 2). Desde la invocación al enfoque de los grupos natos, esto es declarado por una de las entrevistadas que actualmente vive en el pueblo de Codpa:
Ni siquiera podríamos decir de codpeños que estuvieran haciendo patria acá. Ni siquiera eso. Al final, los que están haciendo patria acá son gente que ha vivido en Arica, que ha vivido en el sur, gente que ha venido de Bolivia, porque los que se creen que tienen raíces y sangre codpeña son los que están en Arica. O sea, ni siquiera viven acá. Para mí al fin y al cabo todos somos chilenos, todos tenemos influencia. Hay una mezcla de 
Bolivia, de Perú, porque este era un territorio peruano. Así que una mezcla de Bolivia, Perú, gente del sur que ha llegado, españoles, así que al final yo creo que es una mezcla de todo. $\mathrm{O}$ sea, yo creo que nadie tiene sangre, sangre codpeña... yo creo que a estas alturas... Pero sí me lo han hecho saber que separan entre codpeños y los que no son de acá (entrevista I27/E20, mujer, 45 años, pueblo de Codpa).

En general los actores extra-valle no poseen originalmente una correspondencia directa con los sistemas de identificación tradicional local, ni con los perfiles socioculturales de los miembros codpeños. Esta alteridad es procesada, reactualizando las relaciones intracomunitarias de vecindad, parentesco e identificación local. Una de las principales vinculaciones que estos actores han establecido con el valle ha sido a través de la descendencia (real/ficticia) y/o la alianza (matrimonio/parejas de hecho) (Figura 3). Además, se han integrado al área productiva, desempeñándose en los ámbitos hortofrutícolas, la construcción, el comercio y en actividades de asistencia a los miembros envejecidos del valle. Respecto a este último punto, la misma entrevistada nos señaló lo siguiente:

Hay gente que se ofrece para trabajar en la chacra. Son gente que viene de Arica. Algunas personas de acá traen gente peruana, o gente boliviana a trabajar acá. Porque también la mano de obra es más barata, no es tan cara. Porque la gente de Arica, primero no saben mucho, y luego cobran más caro los trabajadores de Arica. La gente que viene de Bolivia y Perú conocen, nos conocen a nosotros, yo más o menos los ubico, y los contrata uno por dos días, o tres días, dependiendo del trabajo que uno tiene. Se contratan más hombres, porque claro, es para el trabajo un poquito más pesado, que es tirar pala, no sé, hacer hoyos. Las personas peruanas y bolivianas llegan en La Paloma [bus de transporte], y después se ofrecen, o los mismos vecinos se van pasando la voz: 'tal persona está trabajando'. Si hay trabajo, se busca a la persona. Como somos un pueblito chico, nos conocemos todos. Con los maestros ${ }^{1}$ también: 'maestro, ¿cómo está?'. El maestro se va para Bolivia, y luego regresa. Por ejemplo, el maestro de construcción. Él me ha hecho casi todas las construcciones de la casa, entonces, hay un lazo de años, de amistad (entrevista I27/E20, mujer, 45 años, pueblo de Codpa).

En este grupo existe una diferencia interna entre los afuerinos transitorios (que suelen desarrollar labores agrícolas) y los afuerinos arraigados que poseen una residencia permanente. Entre estos últimos, la población distingue además entre quienes han comprado sus terrenos y viviendas, y aquellos que residen en lugares que no son de su propiedad o que los han adquirido informalmente (Figura 3). La forma de adquisición de estos terrenos es descrita claramente por una de nuestras entrevistadas:

La mayoría de las personas tenían terrenos en varios lados. Algunos heredados, algunos tomados, algunos apropiados en la medida del tiempo. Muchas veces los terrenos no estaban regularizados, y se vendían así, a la palabra. Porque si alguien le daba su palabra, era valorizada. Ahora no, ahora si no está escrita en el papel, no vale (entrevista I8/E7, mujer, 35 años, pueblo de Codpa).

\section{Dinámicas Familiares y Parentesco}

El parentesco es uno de los soportes claves de la adscripción e identificación local codpeña, el cual integra diversos órdenes de interacción tanto en el espacio del valle como del extra-valle. En este marco, los actores van estableciendo vínculos que generan una serie de diferenciaciones comunitarias, dando cuenta de la operación de una lógica específica. En este apartado analizaremos cómo los vínculos que se establecen con los apellidos, las alianzas y el compadrazgo, juegan un rol clave en la configuración de este ámbito.

\section{El peso de los históricos}

En el Valle de Codpa existen apellidos locales que son identificados y utilizados por los actores para establecer una serie de referencias y diferenciaciones internas. En primer lugar, hemos podido constatar que los apellidos de los miembros varones se integran siguiendo mecanismos de alianza exogámica. En segundo lugar, si nos centramos en la reproducción y adopción de los apellidos, advertimos que éstos han contribuido a la conformación de sistemas de identificación local que permiten diferenciar a los miembros según el pueblo o sector del valle al cual pertenecen, variando de dos a tres generaciones (Tabla 1). Uno de los entrevistados del pueblo de Codpa describió así la situación:

Todos somos codpeños, cuando nuestros padres y abuelos fueron de acá. De afuera vemos así. Pero acá, cuando estamos acá, cada uno nos reconocemos si eres del pueblo de Codpa, Guatanave, Guañacagua, Chitita, Ofragía, 
así. Todos sabemos de dónde es alguien o es quién (entrevista I43/E45, hombre, 54 años, sector pueblo de Codpa).

Los actores tienden a reconocer y priorizar el uso social de sus apellidos históricos; es decir, aquellos que la comunidad reconoce como pertenecientes a diferentes zonas del valle, utilizando como base las relaciones de parentesco a través de sus ascendientes. De manera que es usual que las personas se remitan a las antiguas familias de cada sector para establecer la identificación de los "codpeños", lo que les permite discriminar entre personas "natas" y "llegadas". Así, es posible apreciar la existencia de un patrón que se articula desde la ascendencia histórica y que es modulado por un modelo patronímico de transferencias. Además, el sistema es bilateral en la ascendencia reconocible y priman los miembros fundacionales históricos ${ }^{2}$.

En tercer lugar, hemos advertido que en este marco se van incluyendo otros apellidos por alianza siguiendo un patrón patronímico. Aquí se sigue una tendencia cognaticia en su concepción altercentrada, donde los miembros seleccionan entre sus dos pertenencias familiares que los conectan genealógicamente con el valle, para definir su membresía y legitimidad. No obstante, la vigencia agnaticia de estos apellidos no siempre es legitimada socialmente.

\section{Las alianzas}

Las alianzas tienen dos acepciones en el Valle de Codpa: las personas pueden volverse cónyuges (vía civil o religiosa) o "juntarse" (sin mediación civil ni religiosa), como ocurre en gran parte de la región. En ambas situaciones el vínculo implica convivencia y dependencia económica. En algunos casos, los miembros se "juntan" y establecen uniones de hecho, donde el advenimiento de los hijos puede implicar la celebración del matrimonio. En otros casos se mantiene el vínculo de hecho, integrando a los hijos a la dimensión de responsabilidad compartida entre el núcleo reproductivo de ambos y sus familiares directos. Antiguamente existía la distinción entre hijos legítimos y naturales, la cual dependía de si los hijos habían nacido o no dentro del matrimonio formalizado (legal y/o eclesial). Así, existía una diferencia valorativa según el origen de alianza de los miembros: los hijos legítimos eran "bien vistos" según la lógica local, mientras que los "naturales" eran cuestionados por su origen en diversos aspectos de la vida social. Un actor nos relató lo que ocurría al respecto en la década de 1960: "En ese tiempo existían los hijos naturales y los hijos legítimos. Entonces por eso nos casamos. Si no estaríamos juntados hasta ahora. Pero hubiéramos estado conviviendo igual" (entrevista I12/E8, hombre, 64 años, poblados de Guañacagua - Esquiña).

La alianza fue un factor de conexión clave entre los miembros de los diferentes grupos de descendencia de los asentamientos, así como con el resto de actores que habitaban el valle. Podemos resumir, de manera esquemática, los patrones que dominaron el establecimiento de alianzas en el valle de la siguiente forma. En una primera etapa (1940-1960), se siguió un patrón exogámico y se vincularon actores intra y extra valle, al igual que actores de asentamiento litorales, precordilleranos y del altiplano. Este fenómeno responde a las transformaciones socioculturales, económicas y políticas que vivió la zona durante el siglo XIX e inicios del siglo XX, siendo una de sus consecuencias más importantes las dinámicas de (des) y (re) andinización local. En lo siguiente, se mantuvo la lógica exogámica, formándose unidades conyugales o de hecho, pero el vínculo se centró en la ciudad (Arica, principalmente). Para el mantenimiento de las relaciones en el continuo campo-ciudad fue determinante la participación de los actores en festividades, celebraciones y organizaciones colectivas del valle. Aquí existió una suerte de endogamia entre los actores que tenían vínculos con el valle, o bien con personas que poseían perfiles rurales y socioculturales andinos en la zona. Por otro lado, cuando se establecían alianzas con miembros urbanos, éstos eran integrados gradualmente en las dinámicas familiares y comunitarias, siendo esencial la participación en espacios festivo-rituales y en organizaciones civiles de tipo cultural-identitarias, como mencionamos anteriormente.

La alianza ha sido un mecanismo complementario entre las identidades colectivas y geográficas del valle, constituyéndose usualmente por oposición simbólica a los actores identificados como afuerinos o llegados. Además, se revela como un tipo de vínculo que va incorporando a individuos de diversos perfiles a las dinámicas locales, activando así la cooperación y la solidaridad restringidas.

\section{El compadrazgo}

Una práctica vigente de parentesco ficticio es el compadrazgo ${ }^{3}$. Se basa en el establecimiento de un vínculo entre padrino/madrina, ahijado(a) y los padres, lo cual conlleva la aceptación de ciertas responsabilidades que poseen los padrinos con sus ahijados, entre otros aspectos. Un entrevistado residente de Guañacagua nos señaló:

El tema de padrino y madrina es bíblico. Éste es un invento de la parte eclesiástica. 


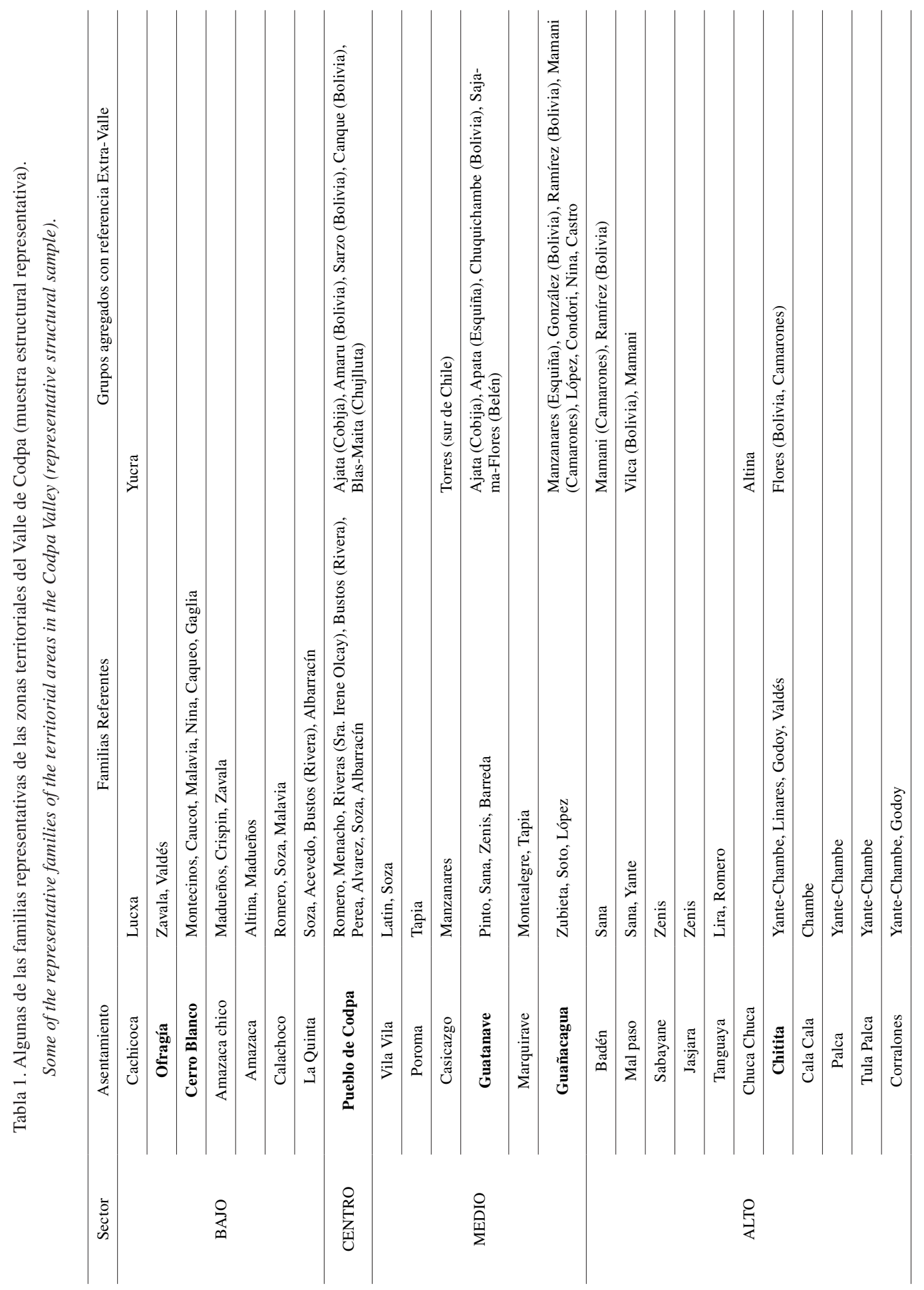


Del Obispo por 1700, inventaron padrino y madrina. Y de ahí quedaron pa' [sic] acá. Padrino y madrina es una responsabilidad, y una cercanía que siempre después uno reconoce. Por ejemplo, dice compadre o comadre. Pero la palabra es como padre o como madre, esa es la palabra (entrevista I12/E8, hombre, 64 años, poblados de Guañacagua - Esquiña).

El compadrazgo genera relaciones familiares que van actuando como elementos de proximidad y se materializan en diversos órdenes y situaciones, como la provisión de bienestar a los hijos, la compraventa preferente de predios y derechos de agua del área, entre otros. Localmente el compadrazgo responde a un mecanismo de inclusión restringida que remite a la afinidad entre los contrayentes y su tipo de vinculación:

Uno le propone que si quieren ser padrinos las personas. Uno dice: 'Tú a mí me caes bien, eres como de la familia, y por eso te propongo que seas el padrino de mi hijo. ¿Tú aceptas mi proposición?'Y Y ahí ve si acepta o no. Es una proposición de los padres de la guagua. No todos aceptan (entrevista I3/E21, mujer, 31 años, poblado de Guatanave).

El compadrazgo involucra la consagración de una serie de derechos y obligaciones específicas entre los celebrantes. En general, son arreglos que asumen los padrinos frente a los padres del ahijado o la ahijada, pasando a ser estos últimos medios de obligación y complicidad. Los padrinos también pueden tener vínculo de alianza entre sí. El vínculo es un acuerdo de "palabra" que se materializa ritualmente con un bautizo católico, con la ceremonia andina denominada "corte de pelo" $\mathrm{O}$ con ambos complementariamente. De hecho, pueden tenerse padrinos diferentes para cada uno de estos ritos, estableciendo vínculos diferentes entre los celebrantes directos.

Gracias al compadrazgo se van constituyendo relaciones específicas y exclusivas que se proyectan en distintas esferas sociales, económicas, políticas y festivas. El vínculo central es la colaboración y apoyo que entregan los padrinos en la crianza de sus ahijados en diferentes etapas de vida, como bien señaló antes nuestro entrevistado de Guañacagua. A través de esta práctica los miembros locales del valle fortalecen su comunalidad y endogamia territorial, basados en el afincamiento de su identificación con los asentamientos históricos.

Esta práctica también es adoptada por los migrantes indígenas de origen boliviano que han arribado al valle, siendo utilizada muchas veces como mecanismo de integración social. En este plano, luego de la adquisición de residencia en la localidad y/o compra de terrenos, se van incluyendo a los asentamientos otros sujetos colectivos cuyo arraigo está determinado por su ocupación en el valle (en muchas ocasiones varios), así como en otros pisos ecológicos, según el perfil migrante y su matriz sociocultural (Figuras 2 y 3 ).

\section{Discusión y Consideraciones Finales}

Hemos podido ver que la dinámica de la migración y movilidad campo-ciudad que se intensificó a lo largo del siglo XX en el norte de Chile, fue clave en la configuración de un patrón residencial, la reproducción poblacional y la identificación de la población del Valle de Codpa.

Desde entonces, la ciudad y el campo se conectaron como espacios diversificados de la producción y reproducción de los grupos domésticos, complejizando los vínculos de sus miembros y prolongando sus esferas de interacción a nivel regional. En esta misma línea, y haciendo eco de una serie de autores (Golte 2012; Gundermann y González 2008, 2009b; Malengreau 2008; Paerregaard 2010, 2011), también advertimos esta complejización debido a la translocalización de las relaciones sociales, la cual está relacionada con la integración de las poblaciones a los modelos de desarrollo y modernización regional.

En este punto seguimos la senda de los estudios que han sido críticos con el uso conceptual de la discontinuidad campo-ciudad y que simultáneamente proponen avanzar hacia una mayor reflexividad en el uso de nociones como territorio y población. Básicamente porque la migración no solo provocó un (relativo) despoblamiento de la zona de estudio, sino también la complejización de las relaciones sociales y la interacción entre el campo y la ciudad (Albó 2000; Carrasco y González 2014; González 2007; Gundermann y González 2008), como pudimos apreciar también en nuestro estudio.

En este escenario, las motivaciones educacionales y laborales fueron capitales en la decisión de emigrar y en la elección del destino primario: la ciudad de Arica. Esto coincide con los hallazgos previos de autores que trabajaron en otras zonas de precordillera y del altiplano norte y sur (Gavilán y Carrasco 2009; González 1990, 1996, 1997, 2007; Tabilo et al. $1995)^{5}$. Junto a ello se produjeron prácticas sociales que hicieron posible la inserción urbana de los actores, como la implementación de estrategias residenciales y la adquisición de viviendas propia en Arica. Esto transformó también la fisonomía por sexo y edad de los asentamientos locales, donde se 
concentraron las cohortes de mayor edad (adulto mayor), mientras que las cohortes más jóvenes que se radicaron de manera permanente en Arica sufrían muchas veces la relativa marginalización del mercado formal.

Esta reconfiguración sociocultural afectó directamente a las dinámicas familiares y de parentesco. La evidencia muestra que entre los habitantes del Valle de Codpa ha predominado la endogamia territorial como uno de los factores más importantes en la constitución de las alianzas. No obstante, también se han generado diversas diferenciaciones intracomunitarias donde el parentesco y su origen histórico han sido elementos relevantes. Concretamente, hemos advertido que existen diversas dinámicas de exclusión de los actores extra-valles que se han instalado en Codpa, las que se manifiestan entre sus miembros bajo la distinción entre "nosotros" y los "otros", definidos estos últimos como los agentes extra-valle que se incorporan a la dinámica local. En este contexto, los agentes extra-valle han sobrellevado esta situación estableciendo formas de integración entre los diversos actores que residen en el valle a través de las alianzas, el compadrazgo y la participación en festividades, ritos y organizaciones culturales-identitarias.

Por último, también hemos podido apreciar cómo muchas dinámicas comunitarias que tienen como referencia al parentesco son esenciales para definir la membresía e identificación local. Así, nuestra evidencia etnográfica muestra que las identificaciones utilizadas en Codpa pueden ser vistas como negociaciones que suelen seguir un esquema concéntrico y jerarquizado, donde el parentesco cognaticio dirigido hacia miembros históricos es clave en la identificación de los actores. Esto ha permitido la generación de un acervo de identificaciones colectivas y locales referidas a los diferentes asentamientos del valle, donde la vinculación entre la referencia parental (apellido) y geográfica (asentamiento) ha sido relevante. No obstante, tal diferenciación también integra en su funcionamiento a otros miembros residentes y a los emigrados, ordenando las relaciones cotidianas, festivo-rituales y organizacionales. Consideramos que esto da cuenta de la operación de una lógica cultural andina específica que adopta instrumentalmente a los énfasis ontológicos aymara y/o quechua de acuerdo con la propuesta etnogubernamental instalada desde inicios de la década de 1990 en la zona ${ }^{6}$, siendo mucho más acorde con los procesos históricos de identificación locales asociados a las dinámicas de complejización de la frontera (trans) nacional, conforme a la (re)producción de pautas consuetudinarias y étnicas del territorio ancestral indígena, así como de las distinciones geopolíticas en el área.

Agradecimientos: Este artículo es resultado de los proyectos PLU160025 (CONICYT) y FCS-IN 1405 (Universidad de Chile). Los autores agradecen a CONICYT, Programa Formación de Capital Humano Avanzado, Becas Chile Doctorado 2014 (Folio $\left.\mathrm{N}^{\circ} 72150364\right)$ y Beca BIO Fulbright-CONICYT 2017. Finalmente, los autores agradecen también a los evaluadores por sus valiosos comentarios y sugerencias, y a todos los participantes de este estudio del Valle de Codpa.

\section{Referencias Citadas}

\begin{abstract}
Albó, X. 1972. Esposos, suegros y padrinos entre los aymara. Pumapunku 6:20-34.
\end{abstract}

Albó, X. 2000. Aymaras entre Bolivia, Perú y Chile. Estudios Atacameños 19:43-73.

Bähr, J. 1980. Migraciones en el norte de grande de Chile. Resultados de un análisis de movimientos migratorios entre los años 1965 y 1970. Revista de Geografía Norte Grande 7:3-20.

Bähr, J. 1985. Agriculture, copper mining, and migration in the Andean Cordillera of Northern Chile. Mountain Research and Development 5 (3):279-290.

Carrasco, A.M. y H. González 2012. Movilidad poblacional. Un ajuste estructural a la nueva realidad postcomunal de los Aymara del norte de Chile. Actas III Congreso Latinoamericano de Antropología (ALA). Antropologías en Movimiento. Ideas desde un Sur Contemporáneo, pp. 1-12. Universidad de Chile, Santiago.

Carrasco, A.M. y H. González 2014. Movilidad poblacional y procesos de articulación rural-urbano entre los aymara del norte de Chile. Si Somos Americanos 14 (2):217-232.
Castro, M. 1982. Estrategias socioculturales de subsistencia en las comunidades Aymaras altoandinas, en el interior de la provincia de Arica, Parinacota. En Las Poblaciones Humanas del Altiplano Chileno: Aspectos Genéticos, Reproductivos y Socioculturales Vol. II, editado por A. Veloso M. y E. Bustos, pp. 99-132. MAB-6 UNESCO, Santiago.

Castro, M. 1997. El campesinado altoandino del Norte de Chile. En El Altiplano. Ciencia y conciencia en los Andes. II Simposio Internacional de estudios altiplánicos, pp. 243-253. Universidad de Chile, Santiago.

Dubet, F. 1987. De la sociología de la identidad a la sociología del sujeto. Estudios Sociológicos 21 (7):519- 545.

Gavilán, V. y A. Carrasco 2009. Festividades andinas y religiosidad en el norte chileno. Chungara Revista de Antropología Chilena 41 (1):101-112.

Gölte, J. 2012. Migraciones o movilidad social desterritorializada. En No hay País más Diverso. Compendio de la Antropología Peruana II, editado por C. Degregori, P. Sendón y P. Sandoval, pp. 247-288. Instituto de Estudios Peruanos, Lima. 
González, H. 1990. Timar, Diagnóstico Socioeconómico. Acerca de la Utilización de dos Espacios Económicos: el Campo y la Ciudad. Taller de Estudios Andinos, Arica.

González, H. 1996. Características de la Migración Campo Ciudad entre los Aymara del Norte de Chile. Corporación Norte Grande, Arica.

González, H. 2007. Comunidad rural en crisis o comunidad translocalizada entre los aymara del norte de Chile. Actas del $6^{\circ}$ Congreso Chileno de Antropología, Tomo I, pp. 537-550. Colegio de Antropólogos de Chile, Santiago.

González, H., y H. Gundermann 1996. Organizaciones aimaras, identidad étnica e integración. En La Integración Surandina. Cinco Siglos Después, editado por X. Albó, M. Arratia, J. Hidalgo, L. Nuñez, A. Llagostera, M.I. Remy y B. Revesz, pp. 395-416. CBC - Corporación Norte Grande - Taller de Estudios Andinos Universidad Católica del Norte, Cusco.

González, H., H. Gundermann y J. Hidalgo 2014. Comunidad indígena y construcción histórica del espacio entre los aymara del norte de Chile. Chungara Revista de Antropología Chilena 46 (2):233-246

Grebe, M.E. 1986. Migración, identidad y cultura Aymará: puntos de vista del actor. Chungara Revista de Antropología Chilena 16-17:205-223.

Grebe, M.E. 1997. Procesos migratorios, identidad étnica y estrategias adaptativas en las culturas indígenas de Chile: Una perspectiva preliminar. Revista Chilena de Antropología 14:55-68.

Gundermann, H. 1998. Notas acerca de Igualdad, identidad étnica y desarrollo en el norte de Chile. Revista de Ciencias Sociales 8:1-13.

Gundermann, H. 2001. Procesos regionales y población indígena en el Norte de Chile. Un esquema de análisis con base en la continuidad y los cambios de la comunidad indígena. Estudios Atacameños 21:89-112.

Gundermann, H. 2005. Comunidad aymara y conflicto interno sobre la tierra en la región de Tarapacá-Chile. Cuadernos Interculturales 3 (5):43-66.

Gundermann, H. 2013. Procesos étnicos y cultura en los pueblos indígenas en Chile. Alpha 36:93-108.

Gundermann, H. 2018. Los pueblos originarios del norte de Chile y el Estado. Diálogo Andino 55:93-109.

Gundermann, H. y C. Chipana 1986. Antecedentes sobre la Familia Aymara y su Rol de Socialización en un Proceso de Aculturación. Universidad de Tarapacá y Fundación Interamericana, Arica.

Gundermann, H. y H. González 2008. Pautas de integración regional, migración, movilidad y redes sociales en los pueblos indígenas de Chile. Revista Universum 23 (1):82-115.
Gundermann, H. y H. González 2009a. Sujetos sociales andinos, Antropología y Antropólogos en Chile. Alpha 29:105122

Gundermann, H. y H. González 2009b. Sociedades indígenas y conocimiento antropológico. Aymaras y Atacameños de los siglos XIX y XX. Chungara Revista de Antropología Chilena 41 (1):133-164.

Hall, S. 2000. ¿Quién necesita la identidad?”. En En los Márgenes de la Educación, coordinado por R. Buenfil, pp. 227-254. Plaza y Valdés Editores, México D.F.

Harris, O. 2008. Alterities: Kinship and gender. En A Companion to Latin American Anthropology, editado por D. Poole, pp. 276302. Blackwell Publishing, Malden.

Harvey, P. 1998. Los "hechos naturales" de parentesco y género en un contexto andino. En Gente de Carne y Hueso. Las Tramas de Parentesco en los Andes, Tomo II, editado por D. Arnold, pp. 69-82. ILCA/CIASE, La Paz.

Lima, M., D.A. Christie, C. Santoro y C. Latorre 2016. Coupled socio-environmental changes triggered indigenous aymara depopulation of the semiarid Andes of Tarapacá-Chile during the late 19th-20th Centuries. PLoS ONE 11 (8):1-12.

Malengreau, J. 2008. Reproducción identitaria y social en las redes translocales de migrantes de los pueblos andinos. Anthropologica 26:7-32.

Marcus, G.E. y M.M.J. Fischer 1999. Anthropology as Cultural Critique. An Experimental Moment in the Human Sciences. The University of Chicago Press, Chicago.

Navarrete, Z. 2015. ¿Otra vez la identidad? Un concepto necesario pero imposible. Revista Mexicana de Investigación Educativa 65 (20):461-479

Paerregaard, K. 2010. The Show must go on. The role of Fiestas in Andean transnational migration. Latin American Perspectives 37 (5):50-66.

Paerregaard, K. 2011. Globalizing Andean Society: Migration and change in Peru's Peasant Communities. En Vicos and Beyond. A Half Century of Applying Anthropology in Peru, editado por T. Greaves, R. Bolton y F. Zapata, pp. 195-213. Altamira Press, Lanham.

Tabilo, K., F. Venegas y H. González 1995. Las Agrupaciones de Residentes Aymara Urbanos en el Norte de Chile: Adaptación a la Ciudad y Vínculos con las Comunidades de Origen. Corporación Norte Grande, Arica.

Van Vleet, K. 2008. Performing Kinship. Narrative, Gender, and the Intimacies of Power in the Andes. University of Texas Press, Austin.
${ }^{1}$ La palabra maestro es utilizada en la zona para referirse a las personas que de manera cotidiana realizan labores de construcción, albañilería, carpintería e incluso de gasfitería. Antiguamente era utilizado más para designar cierto nivel de experticia y experiencia, de manera particular en el ámbito de la construcción y la albañilería.

${ }^{2}$ El catastro genealógico nos mostró también la presencia de dos fenómenos coadyuvantes: cierta tendencia a transferir a los hijos varones los nombres de sus ascendientes en consonancia con un patrón patrilineal; y, siguiendo una matriz hispana, la adopción de los nombres de los santos patronos de los pueblos como elemento de arraigo.

${ }^{3}$ Esta práctica se asocia a una forma de ritual de parentesco que deriva del padrinazgo católico romano, estableciéndose una relación padrino/madrina-ahijado/a que implican obligaciones, derechos y emociones mutuas, así como entre los padrinos/ madrinas con los padres naturales.

${ }^{4}$ Este rito es más celebrado en la zona altiplánica y en Bolivia, lugar de origen de algunos de los habitantes del valle que aún realizan esta práctica. 
${ }^{5}$ Los autores sostienen también que los soportes de socialización fueron los grupos definidos por lazos de parentesco y de comunidad local. Gavilán y Carrasco (2009) agregan que existe una asociación proporcional entre una mayor escolarización, residencia rural y adscripción católica, con una mayor re-vinculación con las "costumbres" y su reproducción mediante la participación y coordinación de festividades comunitarias.
${ }^{6}$ Esto se refiere especialmente a la promoción pública impulsada por agentes del Estado desde la emergencia de la Ley No 19.253 (1993), y la participación de actores étnicos en el diseño e implementación de la política social indígena. Una de sus consecuencias fue la adopción de clasificaciones aymara y quechua por parte de la población local e indígena regional, en detrimento de una etnicidad afincada en los territorios locales ancestrales. 